certain aspects of metabolism may be more prominent in one tissue than in the other.

We have not found anything in Lundegårdh's rejoinder to warrant discarding our view that the implications for the problem of salt uptake of bioelectric measurements are still obscure-we only wish it were otherwise. Amongst those who favour this line of work there cannot be said to be agreement concerning the nature or origin of the phenomena they investigate. Lundegårdh's re-statement still does not convey to us a clear picture of the boundaries which he regards as the seat of the phenomena he measures ; that is, whether this membrane is one of cells, for example, piliferous layer (epidermis of Lundegårdh), root cortex, or endodermis separating an external and internal intercellular fluid, or is a protoplasmic boundary membrane, across which the phenomena of ion accumulation in cells actually occur. Such phrases as "root tip" relative to electrode measurements require much more precise definition before they convey any anatomical meaning.

To return to the constant ' $k$ ' of anion respiration. It is said to be "fairly constant" for an anion present only as a given salt (although in the experiments with barley roots this function would not be constant even with this restriction). With different cations the value of ' $k$ ' is now said to "change somewhat", and it varies also with the ratio of absorbed anions to cations. So versatile a "constant" seems to us to lack utility.

Our purpose in this and our former communication is to suggest to the general reader the complexity of the problem of salt absorption by living cells, and also that the theory of Prof. Lundegarrdh has not yet been established and generally accepted by plant physiologists. With regard to the quoted work of van Eijk on the salt marsh composite Aster tripolium, we note that it is rather the principle of a salt effect on respiration which van Eijk confirms (with which we are not in disagreement) and not the reality of the special anion effect, which even by van Eijk seems to be regarded as an open question. Van Eijk's values for the quantity " $K$ " do not show that this has a constant value spэcific for each anion.

Finality cannot be obtained by further exchange of views in the columns of NATURE. Although we hope that the present discussion may serve a useful purpose, its continuance in this journal could not be justified.

\title{
STATISTICS AND ENGINEERING PRACTICE
}

$\mathrm{D}^{\mathrm{n}}$ R. B. P. DUDDING and W. J. Jennett, of the G.E.C. Research Laboratories at Wembley, have contributed a paper on "Statistics" to the Institution of Electrical Engineers which was published on January 5 and should prove useful in engineering applications. Although there was no spoken discussion, the authors have made some minor changes so that it can be read as a contribution to a general written discussion which will be concluded not later than February 5.

The theory of statistics as a distinct branch of science did not begin to flourish until the last quarter of the nineteenth century ; in England, the work of Galton and Karl Pearson laid the foundations of the applications of the theory to many fields of science. Research workers in biological sciences and in agricultural industry were the first to turn these more recent advances to practical use. Great interest was stimulated by a series of lectures given by Dr. Shewhart at University College, London, in 1932. Later, the British Standards Institution formed a committee charged with the following terms of reference :

(1) To report on the application and use of statistical methods in standardization and specification of quality ; (2) to draw up a short report which would serve to awaken interest in the application of statistical methods on the part of manufacturers and others concerned with problems of standardization and specification; (3) to consider what encouragement is necessary for the development of research on improved statistical methods and their application to industry; and (4) to consider what steps should be taken to provide for co-operation with bodies in the United States of America and elsewhere instituted for similar objects.

Out of this activity also grew the formation of the Industrial and Agricultural Research Section of the Royal Statistical Society. The meetings of this Section have provided opportunities for technicians employed in industry to meet statisticians and for statisticians to meet and discuss with technical people the difficulties which arise in trying to apply statistical methods to the examination of industrial data. Many institutions have been interested in this development. At the present time, there are few industrial products which are not expected to conform with some standard of quality. Measures are taken to ensure that finished products will conform with quality standards demanded by consumers.

The main object of Messrs. Dudding and Jennett was to emphasize the essential statistical nature of many technical problems and the part that chance plays in many technical decisions, and to demonstrate the need for a technique which will give assistance in making deductions from test data.

The following technical improvements and economies accrue to those industrialists who cultivate the statistical outlook and apply statistical methods to the scrutiny of their data. The errors of judgment arising from ambiguities due to the effect of chance, which lead to incorrect action, are reduced. Development work involving reasonably large-scale production can be planned most economically and the results rightly appraised. The efficiencies of the specifications used can be improved, and simple and efficient systematic methods of presenting data requiring daily serutiny can be readily devised.

The authors explain fully the academic method of considering the frequency distribution of observations by the Gaussian curve, and the use of mean and standard deviations is explained. The importance of the methods given for carrying out specifications which involve sampling is clearly stated.

Numerical examples are included which will help those beginning the study of variance. An example has been given where an experienced engineer lacking statistical knowledge, and the statistician lacking practical knowledge, would probably have come to the same erroneous conclusion. Correct diagnosis of the difficulty in the factory was only possible by a combination of the attributes of the two. 